\title{
A gestão de facilities na manutenção de uma instituição pública
}

Ana Maria da Silva Barbosa barbo.ana@gmail.com

Universidade Federal de Pernambuco (UFPE), Recife, Pernambuco, Brasil.

Taciana de Barros Jerônimo taciana.barros@gmail.com

Universidade Federal de Pernambuco (UFPE), Recife, Pernambuco, Brasil.

Patrícia Tatiana Ferreira Ramos patrícia.tframos@gmail.com Universidade Federal de Pernambuco (UFPE), Recife, Pernambuco, Brasil.

Juliana Karla Rodrigues de Souza Santos

julianakarlarodrigues@hotmail.com

Universidade Federal de Pernambuco (UFPE), Recife, Pernambuco, Brasil.

\section{RESUMO}

O presente artigo se propôs a investigar qual a importância da gestão de facilidades para a manutenção do bem público em uma instituição de ensino superior (UFPE). Assim, foi realizado um estudo de caso na Universidade Federal de Pernambuco, especificamente no âmbito da manutenção predial. O instrumento de coleta de dados utilizado na investigação foi o questionário, aplicado aos administradores, técnicos, gestor/fiscais de contrato e a empresa terceirizada. Os resultados demonstraram que a gestão de facilidades é essencial para a UFPE, principalmente para a manutenção do bem público, embora não seja realizada de maneira adequada pela instituição analisada, demonstrando falha de alinhamento das equipes interna (Administradores, técnicos, gestor e fiscais) e externa (empresa terceirizada).

PALAVRAS-CHAVE: Gestão de facilities. Manutenção. Administração pública. 


\section{INTRODUÇÃO}

A administração pública tem como um dos desafios modificar estruturas burocratizadas, sendo o principal deles transformá-las em empreendedoras e flexíveis, disponibilizando serviços públicos eficientes e de qualidade. (GUIMARÃES, 2000). Para tanto, faz-se necessário o rompimento com os modelos tradicionais de administração dos recursos públicos para a introdução de uma nova cultura de gestão, a exemplo da gestão de facilities.

Esse novo modo de gestão pode ser analisado a partir da gestão de ambientes construídos com base na Facility Management (gestão de facilidades), que segundo Enaud (2014), configura-se em um combinado de ações que possibilita a manutenção da organização em funcionamento ininterrupto. Ao invés de um contrato para cada tipo de serviço, celebra-se apenas um de gestão de facilidades, englobando todos os serviços ou aqueles que mais se relacionam; gerenciando-os de modo eficiente para benefício institucional e das pessoas no recinto construído (ANTONIOLI, 2003).

No contexto dos recintos construídos (edificações), a manutenção é um tema cuja importância tem evoluído, com o uso da norma NBR ABNT 5674 (1999). Essa norma registra que os custos anuais envolvidos na operação e manutenção das edificações em uso, acumulados ao longo da vida útil dos prédios, chegam a ser equivalentes ou até superiores aos seus custos de construção. Outro fato negativo é a atenção inadequada, para com a manutenção das edificações, podendo acarretar a retirada de uso antes de cumprida a sua vida útil projetada, gerando transtornos aos usuários e custos em intensivos serviços de recuperação ou construção de novas edificações.

Por ser relevante para o custo dos imóveis, a manutenção deve ser concebida como uma atividade técnica que exige capacitação apurada. Sendo assim, para se alcançar maior eficiência na gestão de edificações, torna-se essencial uma abordagem fundamentada em procedimentos organizados em um sistema de manutenção que vise ao controle de custos e maximização da satisfação dos usuários sobre as condições oferecidas pelos imóveis (NBR ABNT $5674,1999)$.

Portanto, este artigo visa investigar qual a importância da gestão de facilidades para a manutenção do bem público em uma instituição de ensino superior (UFPE). A relevância deste estudo configurou-se no incentivo ao debate a respeito da importância da facility management para a manutenção predial de instituições públicas.

\section{REFERENCIAL TEÓRICO}

A Facility Management é uma modalidade de gestão que possui notoriedade internacional, conhecida por meio das expressões: facilities management (gestão de facilidades-GF) e facility management (gestão de facilidade), também conhecida por meio da sigla FM (WEISE; SCHULTZ; ROCHA, 2012). A Facility Management trata-se da gestão patrimonial e dos serviços de suporte à atividade de uma instituição, sendo um campo multidisciplinar, considerado atual em relação ao gerenciamento e manutenção de edifícios (MAURÍCIO, 2011). 
Por ser um serviço de apoio a atividade central de uma instituição, a FM deve demostrar que não é apenas um custo necessário, mas um serviço que gera valor (diretamente ou indiretamente) a organização (ATKIN; BILDSTEN, 2017), se configurando em uma especialidade da administração que aprimora e reúne esforços, para facilitar as atividades da organizacionais, em todas as suas áreas (GAMA, 2013). Nesse sentido, de acordo com a International Facility Management Association (IFMA) (2009) " a gestão de facilidades é uma profissão que abrange várias disciplinas para garantir a funcionalidade do ambiente construído através da integração de pessoas, lugar, processos e tecnologia". Como profissão, a FM alcançou maturidade após aproximadamente três décadas e meia de expansão (ROPER, 2017).

Além disso, grande parte das vezes essa forma de gestão está ligada a administração de edifícios públicos (FONTES, 2014), como é o caso deste estudo. Desta forma, são necessários múltiplos e variados conhecimentos à gestão de facilidades, relacionando-se diretamente a essência da administração que, consiste no processo de planejar (escolha de tarefas a serem desempenhadas a fim de atingir os objetivos da instituição), organizar (as tarefas são dispostas de modo que o rendimento dos indivíduos contribua para o sucesso da organização, ou seja, colocar os planos em andamento), dirigir (orientar as atividades da instituição na destinação apropriada) e controlar (processo contínuo de medição de desempenho, comparando o atual com o que fora preestabelecido, e, a partir daí, encontrar novas maneiras de melhorar a produção) o uso de recursos com o propósito de alcançar objetivos organizacionais(CERTO, 2003).

O alinhamento dos objetivos organizacionais estratégicos e também da administração do edifício são o ponto chave da gestão de facilities, que preza pela satisfação dos clientes internos e externos da instituição e na geração de valor para o negócio (FERREIRA, 2005). Entretanto, em pesquisa desenvolvida por Quinello (2010) o autor observou que no Brasil, os profissionais de facilidades, atuam mais na área operacional do que na estratégica, ocupando poucas posições de elevada autoridade.

Já em relação aos serviços gerenciados pela área de facilidades, estão os hard services e os soft services. Os serviços pesados (hard services), envolvem os serviços elétricos, mecânicos, de engenharia, reparações (manutenções) entre outros. Já os serviços de classificados como leves (soft services), englobam recepção, limpeza, materiais de escritórios, dentre outros (RAMOS, 2012).

Obviamente, nem todas essas atividades integradoras que compõem a Facility Management, segundo Martins; Barros; Lima (2014), são inerentes à operação de todas as organizações, sendo a implementação de cada uma delas sujeitas às suas necessidades e processo (mundo dos procedimentos), pessoas (mundo das mentes), tecnologia (mundo dos equipamentos) e especificidades.

Ainda no âmbito das atividades que pertencem a gestão de faciliteis destaca-se neste estudo a manutenção dos edifícios. A manutenção, conforme se verifica em algumas definições elencadas pela Associação Brasileira de Normas Técnicas: constitui todas as ações necessárias para que um item seja conservado ou restaurado de modo a poder permanecer de acordo com a condição especificada (ABNT-TB116, 1975). Já a (NBR ABNT 5462, 1994), que substituiu a (ABNT-TB116, 1975), afirma que a manutenção é a combinação de todas as ações técnicas e administrativas, incluindo as de supervisão, destinadas a manter ou 
recolocar um item em um estado no qual possa desempenhar uma função requerida.

Segundo Costa (2014), os sistemas prediais evidenciam as seguintes características:

a) Flexibilidade - quando o sistema pode ser modificado e adaptado às inovações tecnológicas e evoluções funcionais na vida útil do imóvel.

b) Confiabilidade - quando o edifício oferece o desempenho de operação esperado. Sendo que o aumento dessa confiabilidade depende de um gerenciamento eficiente, agregado à rotina de manutenção e à qualidade dos equipamentos utilizados.

c) Gerenciabilidade - quando há controle no gerenciamento organizacional das Informações, tornando a ação positiva sobre o sistema.

Na UFPE, a manutenção predial se realiza por meio de contrato de terceirização que é uma modalidade que se originou pela necessidade de modernização da gerência de serviços e pela adequação das novas exigências mercadológicas. Nesse sentido, os órgãos públicos passaram a delegar suas atividades secundárias a terceiros, dedicando-se as suas atividades fins (LAPA et al., 2013).

De acordo com Poglich (2010), as atividades de suporte às atividades primárias das organizações, a exemplo das de facilidades, podem pertencer a instituição ou serem realizadas por meio de prestadores de serviços que não fazem parte do quadro funcional da empresa. Contudo, essas atividades de suporte refletem diretamente no desempenho das atividades primárias. Ainda conforme a autor:

Em tempo de recessão, todas as áreas de uma empresa estão focadas na redução de custos. Para além dos processos fulcrais, isto inclui igualmente algumas áreas secundárias. O Outsourcing torna-se uma tarefa chave, cuja solução passa pelo Facility Management (FM), que procura obter mais valor para o mesmo dinheiro ou reduzir custos. O ideal é conseguir alcançar ambos. (POGLICH, 2010, p.3).

Dessa forma, a gestão de facilidades é um campo de alta competitividade, que busca a diminuição dos custos, juntamente com o crescimento do valor dos serviços prestados, sendo necessário o aumento das capacitações profissionais para se atuar nessa área (FONTES, 2014). Ademais, novos materiais e sistemas de elevada tecnologia estão se integrando cada vez mais ao âmbito dos ambientes construídos, assim o futuro da FM, demandará das equipes de trabalho aprendizagem e atualização contínua (ROPER, 2017). Por outro lado, segundo Taboada (2017) o debate da gestão de facilidades deveria fazer parte das instituições desde a fase inicial do projeto, englobando a construção, utilização do ambiente construído e ajustes necessários para preservação do edifício.

Sob outro ponto de vista Haugen e Klungseth (2017), em estudo de revisão de literatura internacional, a respeito dos modos de gerenciamento de Gestão de facilidades no setor público, concluíram que a FM, apesar de ser uma disciplina recente, transformou-se há mais de 25 anos em um serviço relevante para o segmento Público e também para o privado. A prática profissional evoluiu 
consideravelmente e a facility management passou a ser uma disciplina incorporada a programas de ensino superior, que são ofertadas em vários países da Europa e do mundo inteiro, assumindo uma gama de aprendizados oriundos da interação entre pesquisa, prática e educação (HAUGEN; KLUNGSETH, 2017).

Especificamente no âmbito de universidades pública Nigeriana Gbadegesin e Babatunde (2015) investigaram o posicionamento de especialistas a respeito do processo decisório de terceirização na prática de $\mathrm{FM}$ e perceberam que a maior parte dos entrevistados afirmaram que no âmbito prático da FM a terceirização é efetiva.

Com base no exposto nesta seção, percebe-se que a gestão de facilidades é uma atividade de suma importância para o gerenciamento do ambiente construído e que no contexto das intuições públicas (neste caso no da UFPE), as atividades de suporte as atividades fins da instituição são realizadas por meio de contrato de terceirização. Por isso, este estudo investigou a importância da gestão de facilidades para a manutenção do bem público, verificando os procedimentos adotados pelas empresas terceirizadas, a partir das visões dos servidores da organização e empresa terceirizada como pode ser observado na seção seguinte.

\section{METODOLOGIA}

A metodologia utilizada neste estudo é de cunho qualitativo, realizada por meio de estudo de caso na UFPE, buscou responder qual a importância da gestão de facilidades para a manutenção do bem público em uma instituição de ensino superior. A pesquisa qualitativa defende acredita que "[...] um fenômeno pode ser melhor compreendido no contexto em que ocorre e do qual é parte, devendo ser analisado numa perspectiva integrada" (GODOY, 1995, p.21).

Em relação ao estudo de caso, Godoi; Mello; Silva (2006, p. 121) esclarecem que o estudo de caso é "[...] especialmente adequado, quando se quer focar problemas práticos, decorrentes das intrincadas situações individuais e sociais presentes nas atividades, nos procedimentos e nas interações cotidianas".

Nesse sentido, na UFPE, a manutenção predial é realizada por meio de contrato de serviços de terceirização. A terceirização constitui demanda secundária, ou seja, de infraestrutura básica a exemplo da manutenção predial. Como procedimentos de manutenção predial preventiva estão inseridos nesta pesquisa, foi analisado o contrato firmado pela Instituição Federal de Ensino Superior (IFES) - UFPE, no intuito de entender os tipos de atividades incluídas nas obrigações da prestadora do serviço.

Quanto à natureza, a pesquisa tem caráter descritivo. Na concepção de Raupp e Beuren (2009), na pesquisa descritiva, descrever significa identificar, relatar, comparar, entre outros. Neste estudo, a descrição ocorreu por meio dos atores envolvidos no contrato de prestação de serviços de terceirização.

Ao todo, e alinhados ao contrato, dos vinte e seis sujeitos, sendo dezoito Administradores de edifícios, quatro técnicos de edificações, três gestores fiscais do contrato e um representante da empresa contratada, apenas vinte e três se pronunciaram sendo: dezesseis Administradores de edifícios, três técnicos de 
edificações, três gestores fiscais do contrato e um representante da empresa contratada. Esse procedimento viabilizou um comparativo entre as visões dos atores da pesquisa; associado à análise documental.

Em relação à pesquisa documental, foi constituída pelo estudo do processo licitatório que deu origem a contratação de serviço de manutenção predial na UFPE, o contrato atual com os correspondentes aditivos e apostilamentos, bem como o inventário dos imóveis e o relatório extraído do Sistema Integrado de Administração Financeira do Governo Federal (SIAFI), apresentando os valores investidos em manutenção no Campus Recife durante o ano de 2015.

Quanto aos instrumentos de coleta de dados, optou-se pelo uso de questionários (CERVO; BERVIAN; SILVA, 2007), estruturados com perguntas abertas e fechadas específicas para cada grupo de investigados conforme apêndice. Quanto ao método de análise de dados, optou-se por utilizar a análise de conteúdo, na modalidade temática, com base em Bardin (2009).

\section{RESULTADOS}

\section{DOCUMENTAÇÃO ANALISADA}

$\mathrm{Na}$ análise do conteúdo do instrumento contratual, verificaram-se as sistemáticas definidas para a realização das atividades, as categorias dos profissionais vinculados ao objeto, o dimensionamento dos serviços e das áreas físicas contempladas na contratação. Outros aspectos vistos foram os materiais e suprimentos utilizados, as obrigações das partes, contratante e contratada, bem como as informações sobre a gestão do contrato e os critérios de acompanhamento da execução do serviço de manutenção predial na UFPE.

O contrato administrativo em questão (№ 88 de 2014) tem em seu objeto a contratação de empresa especializada em serviços de manutenção predial, preventiva e corretiva, para atender a UFPE Campus Recife, com o serviço de engenharia civil nas seguintes atividades:

As instalações físicas, hidráulicas e sanitárias, das cobertas, das pinturas e da rede de água e esgotos que compreendem pequenas obras e reformas civis.

O objeto do contrato está de acordo com a FM, pois abrange a gestão patrimonial e os serviços de suporte à atividade de uma instituição (UFPE) (MAURíclO, 2011). Assim, é considerada uma atividade de suporte que é delegada a terceiros (POGLICH, 2010, LAPA, 2013).

As áreas físicas externas do Campus Recife estão dimensionadas em $1.390 .174 \mathrm{~m} 2$, compostas por vias públicas pavimentadas, estacionamentos, campinas gramadas, áreas com vegetação arbustiva e de grande porte, lagoa do nascente, leito e margens do Riacho do Cavouco.

Assim, os prédios foram organizados por tipos de instalações de acordo com as seguintes finalidades:

a) Administrativa: composta pelas secretarias, gabinetes e auditórios;

b) Ensino e Pesquisa: composta pelas salas de aula e laboratórios; 
c)Infraestrutura: composta pela Prefeitura da Cidade Universitária (PCU) e

d) Moradia firmada pelas Casas dos estudantes universitários - feminina e masculina.

Quanto à sistemática, os serviços são realizados com suporte de cento e sessenta e um postos (CONTRATO ADMINISTRATIVO № 88, 2014). No que se refere ao inventário dos bens imóveis atualizados até 2015 , há 119 edificações no Campus Recife da UFPE, com valor de $\mathrm{R} \$ 307.014 .909,49$. Considerando que o montante dos imóveis pertencentes à UFPE, nos três Campi, somam R\$ 362.031.372,83. O Campus Recife corresponde a 84,80\% deste total. Embora o inventário apresente toda infraestrutura física da Instituição, essa avaliação destacou apenas os seis centros e um órgão suplementar escolhido para a pesquisa como segue:1) CCS - Centro de Ciências da Saúde - composto por dezessete unidades, resultando em $45.464,51 \mathrm{~m} 2$; 2) CCSA - Centro de Ciências Sociais Aplicadas - composto por duas edificações, medindo $16.030,00 \mathrm{m2}$; 3) Cln - Centro de Informática - funciona com toda sua especificidade em apenas um imóvel, medindo $4.628,23 \mathrm{~m}^{2}$ de área construída 4) $\mathrm{CFCH}$ - Centro de Filosofia e Ciências Humanas - a mais alta edificação da UFPE estruturada em 25.485,83m2; 5) CTG - Centro de Tecnologia e Geociências - formado por vinte edificações com área construída, medindo $57.625,23 \mathrm{~m} 2$ e a 6)BC - Biblioteca Central - Órgão Suplementar, com apenas uma unidade sede e área construída medindo $5.593,42 \mathrm{~m} 2$.

Ademais, outro documento analisado foi o relatório do SIAFI, no qual foi verificado os investimentos que, na $\mathrm{FM}$, devem ser enxergados como um serviço que gera valor (ATKIN; BILDSTEN, 2017). Nesse relatório consta que a UFPE investiu $\mathrm{R} \$$ 7.435.397,49 estando inclusos $\mathrm{R} \$ 1$ 141.214,11 correspondentes à primeira repactuação de valor, firmada no termo de apostila já mencionado. Esse montante foi pago em doze mensalidades, de janeiro a dezembro do ano de 2015 , sendo duas em janeiro e fevereiro, no valor de $\mathrm{R} \$ 508.063,94$, e dez mensalidades de março a dezembro, no valor de $\mathrm{R} \$ 532.924,68$ cada uma delas. Outro dado percebido é que, desse montante, a UFPE creditou cerca de $87 \%$ na conta da empresa terceirizada por meio do seu serviço de caixa central e recolheu $13 \%$ do valor supramencionado aos cofres do governo, correspondentes aos impostos, fracionando de acordo com o percentual definido legalmente para cada tributo.

\section{QUESTIONÁRIO}

As respostas dos dezesseis Administradores de edifícios, tratados daqui em diante como ( $A D M$ 's, $A D M 1, A D M 2, A D M 3, \ldots$ ) mostram que em relação à periodicidade das inspeções nos edifícios, constataram-se fragilidades nas respostas dos ADM's, por variarem entre diariamente, semanalmente, quinzenalmente, mensalmente, semestralmente e anualmente. Outros ADM's desconhecem e outros declararam atuar com medidas corretivas.

Quanto a forma de identificação de necessidades de manutenção, o ADM6 avaliou que as inspeções ocorrem mensalmente, entretanto as necessidades são identificadas por solicitação dos usuários, percebendo-se uma incoerência nessas respostas. Sendo assim, se as necessidades são conhecidas quando os usuários se 
manifestam, pode-se perceber a inexistência de manutenção preventiva. 0 ADM7, embora tenha afirmado a existência de inspeção anual, na sua avaliação, afirma que a carência de manutenção é identificada quando os usuários solicitam, nos fazendo entender que a periodicidade da atividade, naquele edifício, deve ser reduzida. Para os ADM's 10 e 12 há atuação corretiva e a identificação de necessidade mediante solicitação do usuário. Os demais ADM's destacaram a realização de inspeções e que, tanto através destas como por solicitação do usuário, identificam-se as necessidades de manutenção.

Para os ADM's 1, 3, 4, 10,11,13, 14 e 16, nas questões sobre as principais dificuldades, durante a prestação do serviço e sobre os componentes mais difíceis de serem inspecionados, verificou-se que a maior dificuldade para realizar a manutenção decorre da falta de materiais, de equipes exclusivas. Portanto, essa falta de materiais, que é de responsabilidade da UFPE, além de configurar descumprimento contratual, tende a enfraquecer os atos do gestor e fiscais sobre a execução do serviço e fragiliza a cobrança de compromisso da empresa terceirizada. Outras dificuldades apresentadas, como resultados da avaliação foram: idade das edificações; serviços no interior das salas de aula; ruídos; o transitar dos pedestres; serviços na rede elétrica; e acesso ao local da demanda.

No tocante aos itens que requerem atenção especial, por parte da manutenção, os ADM's avaliaram a observância de segurança do trabalho, qualidade e disponibilidade dos materiais em almoxarifado, cobertas, limpeza, controle de pragas, jardinagem, sistemas de elevadores, de condicionadores de ar e de informática, iluminação e hidráulico. Dessa forma, verifica-se que estes aspectos fazem parte da $\mathrm{FM}$, sendo uma forma de gestão que está ligada a administração de edifícios públicos (FONTES, 2014)

Quanto à existência de práticas de segurança de trabalho empregadas no serviço, apenas os ADM's 4 e 16 responderam que não há, sendo que os outros confirmaram a existência delas, citando algumas como: EPIs e EPCs, extintores, brigada de emergência, máscaras, luvas, óculos, capacetes e botas. Responderam também que quem autoriza os requerimentos do serviço de manutenção é qualquer membro da equipe de infraestrutura; em algumas unidades a direção do departamento e em outras a direção do centro.

Quanto a indagação sobre o uso de software para o armazenamento de informações e apoio a decisão e se ele era útil, de fácil operação e se estava atualizado, o ADM1 afirmou que existe, porém não é útil, não está atualizado e não se utiliza regularmente. O ADM10 e 13 discordaram afirmando que, além de atualizado, fazem uso com frequência, enquanto que os outros ADM's afirmaram que não havia software em suas unidades.

\section{Técnicos em edificações}

No que se refere ao o período de inspeções realizadas nos edifícios, apenas o TEC3 informou que era anualmente. As necessidades de manutenção, segundo os TEC's1, 2 e 3, identificam-se por solicitação dos usuários, tendo o TEC2 acrescentado que: "às vezes, quando fazemos visitas a determinados locais, verificamos a necessidade de manutenção e passamos esta informação para o setor responsável". 
Em relação aos principais obstáculos no serviço de manutenção predial no Campus Recife, os TEC's 1 e 3 afirmaram ser a falta de materiais, já o TEC2 foi mais abrangente ressaltou que é necessário a entrega de materiais, equipamentos de segurança e mão-de-obra qualificada, além disso, é preciso o estabelecimento de metas e de um software para que as informações sejam geridas.

No que se refere aos itens que exigem atenção especial na avaliação dos técnicos percebeu-se que os sistemas hidrossanitário e elétrico, telhado pintura, impermeabilização e revestimento estão entre os itens que exigem atenção especial por parte da manutenção. Estes serviços apontados são considerados hard services (RAMOS, 2012).

Por outro lado, as práticas de segurança no trabalho, por meio do uso de equipamento de proteção individual, ainda são escassas.

Por fim, em relação a existência de um software de armazenamento e apoio a decisão sobre a manutenção predial, apenas o TEC3 afirmou a existência de software PCU@tende destinado ao armazenamento de informações que, embora de fácil manuseio, não é útil, encontra-se desatualizado e em desuso.

\section{Gestor e fiscais}

A respeito das inspeções, apenas os GF3 e GF2 se pronunciaram, o GF3 informou que as inspeções não foram implantadas e o GFISC2, mais uma vez, detalhou: " não executamos manutenção preventiva, por falta de material decorrente de processos licitatórios intermináveis, falta de pessoal, edificações antigas, falta de recursos". Os GF's 2 e 3 avaliaram também que as necessidades de manutenção se identificam por solicitações dos usuários; o GF1 não se pronunciou.

Sobre as principais dificuldades, durante a prestação do serviço, apenas GFISC2 afirmou ser a falta de material e GFISC3 se referiu à liberação das áreas. E os elementos que requerem atenção especial, nas avaliações dos GFISC's foram os telhados, instalações elétricas, hidráulicas e sanitárias.

Quanto às práticas de segurança do trabalho, o GFISC2 e GFISC3 citaram o uso de equipamentos de proteção individual (EPI) e de equipamentos de proteção coletiva (EPC). Finalmente, sobre a existência de software de armazenamento e apoio a decisão, apenas os GF's 2 e 3 responderam que não há, mas o GF2 afirmou que está sendo adquirido e o GF1 respondeu que desconhece.

\section{Análise da empresa contratada}

No que se refere as inspeções, a empresa respondeu que as inspeções acontecem semanalmente/diariamente são de pequeno porte, como verificação do sistema de abastecimento de água e das cobertas com varrição, verificação dos sistemas de bombas das edificações, dentre outros. 
Em relação aos principais obstáculos na implantação do contrato de prestação de serviço, decorreram da burocracia e de eventuais falhas na entrega de diversos materiais que são de fornecimento obrigatório da UFPE, e a liberação do local para iniciar os serviços. E os elementos que demandam atenção especial por parte da manutenção, são as cobertas das edificações, sistema de abastecimento de água e esgoto, sistema de geradores e de rede interna de iluminação e externa.

Em relação às práticas de segurança de trabalho, a empresa utiliza EPI's, uso de cinto de segurança e capacete em serviços andaimes, porém a maior preocupação é no que se refere aos serviços de coberta, os quais não possuem pontos de apoio que possibilitem a utilização de cintos de segurança em serviços que envolvam altura.

A respeito de software para armazenamento de informações e tomada de decisão sobre manutenção predial, na UFPE, A empresa afirmou detalhando que a ferramenta é útil, atualizada e de fácil operação, destacando que: "[...] o software utilizado é de iniciativa da empresa [...], desde a sua concepção, sua implantação e utilização diária [...]. O mesmo serve de controle de serviços que são úteis na elaboração de relatórios mensais. " Dessa forma, a partir dos dados expostos, a seção a seguir é composta pela análise dos resultados.

\section{ANÁLISE DOS RESULTADOS}

$\mathrm{Na}$ análise dos questionários, percebeu-se que a manutenção predial inclui outros serviços não pertencentes à atividade finalística da instituição na concepção de diversos Administradores de edifícios. Neste sentido, Martins; Barros; Lima (2014) afirmam que nem todas essas atividades integradoras que compõem a Facility Management, são inerentes à operação de todas as organizações, sendo a implementação de cada uma delas sujeitas às suas necessidades e processo (mundo dos procedimentos), pessoas (mundo das mentes), tecnologia (mundo dos equipamentos) e especificidades.

Para os ADM's, manutenção predial compreende os serviços de infraestrutura como um todo: limpeza, manutenção de equipamentos condicionadores de ar, de elevadores dentre outros. Estes dados corroboram com Ramos (2012), segundo este autor, em relação aos serviços gerenciados pela área de facilidades, estão os hard services e os soft services. Os serviços pesados (hard services), envolvem os serviços elétricos, mecânicos, de engenharia, reparações (manutenções) entre outros. Já os serviços de classificados como leves (soft services), englobam recepção, limpeza, materiais de escritórios, dentre outros.

Quanto ao aspecto inspeções, verificou-se que há opiniões que diferem, isto é, não há, de forma clara, um estabelecimento de periodicidade para inspeção nos edifícios, enquanto alguns informaram que há diariamente, outros responderam anualmente, bem como há alguns que desconhecem a existência de uma periodicidade de manutenção.

Quanto ao aspecto dificuldades durante a prestação do serviço de manutenção predial, foi apontado por todos os respondentes (equipe interna e empresa prestadora do serviço) que o principal entrave na UFPE é a falta de materiais, outros obstáculos citados foram: equipes de trabalho, idade das 
edificações, serviços internos em geral, equipamentos e software e liberação de áreas. Estas respostas demonstram que novos materiais e sistemas de elevada tecnologia, no caso do software, estão se integrando cada vez mais ao âmbito dos ambientes construídos (ROPER, 2017). Em relação aos itens que requerem atenção especial, os respondentes informaram alguns aspectos em comum: cobertas e iluminação (ADM's e empresa), telhado, hidráulica e sanitátia (TEC's e GF's) e sistema hidráulico (ADM's, TEC's, GF's e a empresa).

No que concerne as práticas de segurança no trabalho, os ADM's, GF's e empresa tiveram pensamentos congruentes em relação ao uso de EPI's e EPC's., no entanto os técnicos alegaram que o uso ainda é escasso. Quanto ao uso de software de armazenamento de informações e tomada de decisão sobre a manutenção predial, as opiniões foram divergentes, alguns afirmaram que existe e outros que não existe.

Nesses depoimentos, constatou-se a importância da Gestão de Facilidades sustentada por Maurício (2011), principalmente devido à importância da manutenção para o pleno funcionamento dos imóveis na UFPE, uma vez que A Facility Management trata-se da gestão patrimonial e os serviços de suporte à atividade de uma instituição, sendo um campo multidisciplinar, considerado atual em relação ao gerenciamento e manutenção de edifícios.

\section{CONCLUSÕES}

A partir das análises identificou-se que, apesar de não ser utilizada de maneira adequada, a gestão de facilidades é essencial para a UFPE, principalmente para a manutenção do bem público, possibilitando o pleno funcionamento da UFPE. Este resultado corrobora com a pesquisa de Haugen e Klungseth (2017) que concluíram que a FM, apesar de ser uma disciplina recente, transformou-se há mais de 25 anos em um serviço relevante para o segmento Público.

Uma gestão de facilidades eficaz, é fundamental para que a UFPE invista na disponibilidade dos materiais de consumo, e, havendo morosidade no processo de aquisição face aos trâmites legais e pela variedade e especificidades dos itens, sugere-se contratar a manutenção predial incluindo o fornecimento desses insumos na responsabilidade da empresa prestadora do serviço. Afinal, a Instituição arcou com despesas fixas, para ter suas edificações bem cuidadas e conservadas, todavia as evidências indicaram muitos sinais de ausência de manutenção preventiva e pontos carentes de reparos.

Ademais, considera-se necessário disseminar as obrigações contratuais da empresa prestadora de serviço de manutenção predial e deveres da UFPE, por meio de capacitação a todos os envolvidos (servidores e contratados).

Em relação as limitações do estudo, destaca-se dificuldades na coleta de dados em virtude da indisponibilidade dos investigados no período de realização do estudo. Como sugestão de pesquisa futura, recomenda-se um estudo comparativo sobre os impactos da FM em instituições de ensino superior públicas no Estado de Pernambuco. 


\title{
The management of facilities in the maintenance of a public institution
}

\begin{abstract}
This paper aims to investigate the importance of managing facilities for the maintenance of the public good in a higher education institution (UFPE). Thus, a case study was conducted at the Federal University of Pernambuco, except for the scope of building maintenance. The data collection instrument used in the investigation was a questionnaire, applied to controls, technicians, contract manager / inspector and a third party company. The results showed that facilities management is essential for UFPE, especially for the maintenance of public welfare, although it is not performed properly by the institution analyzed, showing a lack of alignment of internal teams (Administrators, technicians, managers and inspectors). and outsourced company.
\end{abstract}

KEYWORDS: Facilities management. Maintenance. Public administration. 


\section{REFERÊNCIAS}

ATKIN, B.; BILDSTEN, L. A future for facility management. Construction Innovation, v. 17, n. 2, p. 116-124, 2017. crossref

ANTONIOLI, P. E. Estudo crítico sobre subsídios conceituais para suporte do planejamento de sistemas de gerenciamento de facilidades em edificações produtivas. 2003. 256 f. Dissertação (Mestrado em Engenharia) -Escola Politécnica, Universidade de São Paulo, São Paulo, 2003.

BARDIN, L. Análise de conteúdo. 4. ed. Lisboa, Portugal: Edições 70, 2009

BRASIL. NBR ABNT-TB 116 (1975). Confiabilidade de equipamentos e componentes eletrônicos: Termos básicos e definições. Disponível em: <http://www.abntcatalogo.com.br/norma.aspx?ID=60906 > Acesso em: 11 jun. 2015

BRASIL. NBR ABNT 5462 (1994). Confiabilidade e mantenabilidade. Disponível em: $\quad$ https://www.target.com.br/produtos/normas-tecnicas/29220/nbr5462confiabilidade-e-mantenabilidade> Acesso em: 05 jul. 2015.

BRASIL. NBR ABNT 5674 (1999). Manutenção de edificações. Disponível em:

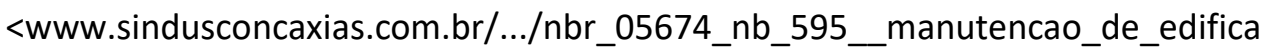
coes_.>. Acesso em: $17 \mathrm{fev} .15$.

CERVO, A. L. ; BERVIAN, P. A. ; SILVA, R. Metodologia científica. 6. ed. São Paulo: Person Prentice Hall, 2007. 158 p.

CERTO, S. C. Administração moderna. 9. ed. São Paulo: Prentice Hall, 2003.

COSTA, R. S. Gerenciamento de facilidades em sistema de transporte vertical mecanizado de passageiros. 2014. 87 f. Monografia (MBA em Gerenciamento de Facilidades) - Universidade de São Paulo, São Paulo, 2014.

ENAUD, P. As quatro fases de evolução da gestão de facilities no mundo: $O$ crescimento desta carreira que agrega valor ao pacote de serviços. Revista Infra, Ed. 163, abr. 2014.2 Disponível em: <http://www.revistainfra.com.br/portal/Textos/?Artigos/14556/As-quatro-fasesde-evolu\%C3\%A7\%C3\%A3o-da-gest\%C3\%A3o-de-facilities-no-mundo>. Acesso em: 15 nov. 2015.

FERREIRA, F. P. Gestão de facilidades: estudo exploratório da prática em empresas instaladas na região metropolitana de Porto Alegre. 2005. $152 \mathrm{f}$. Dissertação (Mestrado)-Programa de Pós-graduação em Engenharia Civil, Universidade Federal do Rio Grande do Sul. 2005.

FONTES, A.D.R. Proposta de Sistema de Gestão da Manutenção de Edifícios Suportado por Ferramentas BIM.2014. (Mestrado Integrado em Engenharia Civil) - Departamento de Engenharia Civil, Faculdade de Engenharia da Universidade do Porto, Porto, Portugal, 2014.

GAMA, G. O. Facilities management: a importância da administração de facilidades nas organizações.Disponívelem:<http://www.excelenciaemgestao.org/Portals/2/doc uments/cneg9/anais/T13_2013_0 028.pdf>. Acesso em: 13 set. 2015. 
GBADEGESIN, J. T.; BABATUNDE, T. O. Investigating experts' opinion on outsourcing decision in facilities management practice in public Universities in Nigeria. Journal of Facilities Management, v. 13, n. 1, p. 27-44, 2015. crossref

GODOY, A. S. Pesquisa Qualitativa: tipos fundamentais. Revista de Administração de

Empresas - RAE, v. 35, n.3, p.20-29, 1995. crossref

GUIMARÃES, T.A. A nova administração pública e a abordagem da competência. Revista de Administração Pública, v.34, n.3, p. 125-140, 2000.

HAUGEN, T. B.; KLUNGSETH, N. J. In-house or outsourcing FM services in the public sector: a review of 25 years research and development. Journal of Facilities Management, v. 15, n. 3, 2017. crossref

IFMA: International Facilities Management Association. Disponível em: <http://www.ifma.org/>. Acesso em: 16 out. 2017.

LAPA, J. R. C. S. et al. A terceirização dos serviços de limpeza e conservação na Universidade Federal de Santa Catarina (UFSC): Estudo de caso sobre a gestão e fiscalização desses serviços no Centro de Comunicação e Expressão (CCE). In: COLOQUIO DE GESTIÓN UNIVERSITARIA EM AMÉRICAS, 13., 2013, Florianópolis, SC. Anais eletrônicos.Florianópolis, SC: UFSC, 2013. Disponível em: <https://repositorio.ufsc.br>. Acesso em: 02 nov. 2014.

QUINELLO, R. Inovação e melhoria nas facilidades e desempenho operacional. 2010. Tese (Doutorado). Universidade de São Paulo, São Paulo, 2010.

MARTINS, H. C.; BARROS, D. F.; LIMA, D. F. P. Terceirizar a gestão do cliente? Um estudo sobre o impacto da terceirização da atividade de facilities management na satisfação de clientes organizacionais. Sociedade, Contabilidade e Gestão, v. 9, n. 1, p. 82-104, 2014. crossref

MAURíCIO, F. M. M. P. Aplicação de Ferramentas de Facility Management à Manutenção Técnica de Edifícios de Serviços. 2011. 159 f. Dissertação (Mestrado em engenharia civil)-Instituto Superior Técnico, Universidade Técnica de Lisboa, Lisboa, 2011.

POGLICH, A. R.R. Tendências e Desenvolvimentos no Facility Management. Aspector, ISS White Paper. 2010.

QUINELLO, R.; NASCIMENTO, P. T. S. O Processo de Inovação sob o Enfoque Institucionalista: Um Estudo Etnográfico na Gestão de Facilidades de uma Montadora do Estado de São Paulo. RAl - Revista de Administração e Inovação, São Paulo, v. 6, n. 1, p. 05-29, 2009.

RAMOS, J.N.M. Gestão de instalações. 2012. Instituto Superior de Engenharia de Lisboa, Lisboa, 2012.

RAUPP, F. M. ; BEUREN, I. M. Metodologia da Pesquisa Aplicável às Ciências Sociais. In: BEUREN, llse Maria (org.). Como Elaborar Trabalhos Monográficos em Contabilidade: teoria e Prática. 3. ed. São Paulo: Atlas, 2009.

ROPER, Kathy O. Facility management maturity and research. Journal of Facilities Management, v. 15, n. 3, 2017. crossref 
TABOADA, N.I.T. Experiência do usuário e o gerenciamento de facilidades hospitalares.2017. Monografia (especialização em gerenciamento de facilidades). Escola Politécnica da Universidade de São Paulo, São Paulo, 2017.

Universidade federal de Pernambuco. SINFRA. Inventário de bens imóveis da UFPE 2015. PROGEST Contrato administrativo no 88. 2014.

WEISE, A. D. ; SCHULTZ, C. A.; ROCHA, R. A. Facility Management: Contextualização e Desenvolvimento. Revista Engenho, Set. 2012. Disponível em: $<$ http://www.portal.anchieta.br/revistas-e livros/engenho/pdf/revista_engenho06.pdf\#page=36>. Acesso em 06 jan. 2016.

\section{APÊNDICES}

* Questionário para o representante da empresa prestadora do serviço de manutenção predial no campus Recife da UFPE

1- Há práticas de segurança de trabalho empregadas no serviço de manutenção predial?

( ) Não

( ) Sim, quais são?

2- Cite o(s) principal(is) obstáculo(s) para implantar os serviços de manutenção predial no Campus de Recife da UFPE.

3- Há algum tipo de software que ajude no armazenamento de informações e tomada de decisão sobre a manutenção predial na UFPE?

( ) Não

( ) Sim-É útil?（） Sim ( ) Não

É de fácil operação? ( ) Sim （） Não

Está atualizado?（） Sim （） Não

4- Com que periodicidade são executadas inspeções gerais nos edifícios?

Anualmente ( )

Dois em dois anos ( )

Outra ( ) Qual?

5-A seu ver, quais componentes prediais requerem atenção especial por parte da manutenção no campus Recife da UFPE? 


\section{* Questionário para os administradores de edifícios}

1- Há algum tipo de software que ajude no armazenamento de informações e tomada de decisão sobre a manutenção predial na UFPE?

( ) Não

( ) Sim-É útil? ( ) Sim ( ) Não

É de fácil operação? ( ) Sim ( ) Não

Está atualizado?（） Sim （） Não

2- - Com que periodicidade são executadas inspeções gerais nos edifícios?

Anualmente ( )

Dois em dois anos ( )

Outra ( ) Qual?

3- Como ocorre a identificação da necessidade de manutenção no edifício em que Você trabalha?

( ) Inspeções periódicas

( ) Solicitação dos usuários

( ) Outros - Especificar

4- A seu ver, quais itens requerem atenção especial por parte da manutenção nesse Centro?

5- Há práticas de segurança de trabalho empregadas no serviço de manutenção predial?

( ) Não

( ) Sim, quais são?

6- Quais as principais dificuldades durante a prestação do serviço de manutenção predial nesse Centro?

7-- Cite três componentes das edificações mais difíceis de serem inspecionados e por que.

$\begin{array}{ll}( & \text { ) Estrutura/alvenaria } \\ ( & \text { ) Telhado } \\ ( & \text { ) Rede de esgoto } \\ ( & \text { ) Peças sanitárias } \\ ( & \text { ) instalações elétricas, hidráulicas e sanitárias } \\ ( & \text { ) Revestimento } \\ ( & \text { ) Piso } \\ ( & \text { ) Impermeabilização } \\ \text { ( ) Outros }\end{array}$




\section{Questionário para os técnicos em edificações}

1- Com que periodicidade são executadas inspeções gerais nos edifícios?

Anualmente ( )

Dois em dois anos ( )

Outra ( ) Qual?

2 Quais as principais dificuldades durante a prestação do serviço de manutenção predial na UFPE Campus Recife?

3 Há algum tipo de software que ajude no armazenamento de informações e tomada de decisão sobre a manutenção predial na UFPE?

( ) Não

( ) Sim-É útil? ( ) Sim ( ) Não

É de fácil operação? ( ) Sim ( ) Não

Está atualizado?（） Sim （） Não

4 A seu ver, quais itens requerem atenção especial por parte da manutenção no Campus Recife da UFPE?

5 Há práticas de segurança de trabalho empregadas no serviço de manutenção predial no Campus Recife da UFPE?

( ) Não

( ) Sim, quais são?

\section{*Questionário para o gestor e fiscais do contrato}

1- Com que periodicidade são executadas inspeções gerais nos sistemas dos edifícios do Campus Recife da UFPE?

Anualmente ( )

Dois em dois anos ( )

Outra ( ) Qual?

2- Como ocorre a identificação da necessidade de manutenção nos edifícios do Campus de Recife da UFPE?

( ) Inspeções periódicas

( ) Solicitação dos usuários

( ) Outros - Especificar 
3 - A seu ver, quais itens requerem atenção especial por parte da manutenção no Campus Recife da UFPE?

$4 \quad$ Há algum tipo de software que ajude no armazenamento de informações e tomada de decisão sobre a manutenção predial na UFPE?

( ) Não

( ) Sim-É útil?（）Sim （）Não

É de fácil operação? ( ) Sim ( ) Não

Está atualizado? ( ) Sim （） Não

5 Há práticas de segurança de trabalho empregadas no serviço de manutenção predial no Campus Recife da UFPE?

( ) Não

( ) Sim, quais são?

6- Quais as principais dificuldades durante a prestação do serviço de manutenção predial na UFPE?

BARBOSA, A.M. S.; JERÔNIMO, T .B.; RAMOS, P.T.F. SANTOS, J. K.R.S. A gestão de facilities na manutenção de uma instituição pública. R. Gest. Industr., Ponta Grossa, v. 16, n. 3, p. 129-146, Jul./Set. 2020. Disponível em: https://periodicos.utfpr.edu.br/revistagi

Correspondência:

Ana Maria da Silva Barbosa

Av. Prof. Moraes Rego, 1235 - Cidade Universitária, Recife, Pernambuco, Brasil

Direito autoral: Este artigo está licenciado sob os termos da Licença Creative Commons-Atribuição 4.0

Internacional.

\section{(c) (i)}

